\title{
Evolution And Persistence Of Students' Astronomy Career Interests: A Gender Study
}

\author{
Zoey Bergstrom, Harvard University, USA \\ Philip Sadler, Harvard-Smithsonian Center for Astrophysics, USA \\ Gerhard Sonnert, Harvard University, USA
}

\begin{abstract}
This article uses U.S. survey data $(N=15,847)$ to characterize the evolution of student interest in an astronomy career in the period between middle school and the beginning of college. We find that middle school students have a relatively high interest in astronomy, which sharply declines with every phase of their education. However, many of the students who leave astronomy - particularly male students - feed heavily into other STEM disciplines. Through statistical modeling, we find that students who spend extracurricular time observing stars, tinkering with mechanical or electrical devices, or reading/watching science or science fiction are significantly more likely than students who do not engage in these activities to hold an interest in pursuing an astronomy career at the end of high school. We also find that females who observe stars during extracurricular time show a greater improvement in their odds of pursuing astronomy than males do. Furthermore, we find that these out-of-school-time activities are better predictors of astronomy interest than commonly studied academic predictors. We discuss the implications of these findings on future extracurricular programming for students.
\end{abstract}

Keywords: Astronomy Education Research; STEM Career Pathways

1

$\mathrm{n}$ a world of relentlessly advancing technology, the need for scientists and engineers is constantly growing (Bureau of Labor Statistics, 2015). The continual improvement of science and mathematics education is crucial to sustaining and strengthening national innovation and research capabilities, as it is to supporting a STEM literate citizenry. Moreover, at present, the nation is subject to a substantial gender gap in the fields of science, technology, engineering, and mathematics (STEM), starting as early as middle school and extending through to the professional world. The field of astronomy is of particular interest: whereas the community of professional astronomers is quite small in numbers, astronomy plays a much larger role in popular science (TV, movies, science fiction novels) than most other STEM fields, giving many young students an initial curiosity about the subject. It is therefore important to investigate what happens to all those students with an early interest in astronomy, and to determine which factors affect the retention of astronomy career interest among students.

The often-used metaphor of a "leaky pipeline" illustrates a common trend in STEM education: for many STEM fields, student interest diminishes at every phase of their education, with an accelerated loss of female students (RiegleCrumb, Moore, \& Ramos-Wada, 2010; Sadler, Sonnert, Hazari, \& Tai, 2012). Students as young as fourth grade already have preconceived notions of physical sciences as male-oriented (Potvin, Hazari, Tai, \& Sadler, 2009), which makes it difficult, already early in the pipeline, to increase or even maintain the number of females who would consider STEM careers. Because female students' rates of departure from STEM differ across various STEM disciplines, it is imperative to determine where the largest gender disparities lie in order to target their causes. Sadler and colleagues' (2012) research has found that the most noteworthy declines in female persistence during high school occur in astronomy and computer science. Numerous researchers have already studied the gender gap in computer science in recent years (Bayer Corp., 2012; Cheryan, Plaut, Davies, \& Steele, 2009; Lagesen, 2007; Margolis, Fisher, \& Miller, 2000; Singh, Allen, Scheckler, \& Darlington, 2005), but there is a dearth of knowledge about factors that affect the retention of students with astronomy career intentions early on in their education, particularly with respect to gender. Most publications that address the gender gap in astronomy focus on underrepresentation among professional 
astronomers, with little reference to what goes on during their education (e.g., Barlow's [1992] journal article titled "Women in Astronomy"). In addition, some research focuses on the students' educational trajectories during college and graduate studies, without specifically analyzing career intentions before that time (Ahlqvist, London, \& Rosenthal, 2013; Slater, 2010).

During students' primary and secondary education, outside-of-school-time (OST) activities provide a unique opportunity for students to self-regulate their learning and explore their own intrinsic motivations, helping them make better informed decisions about their future professions (Bergin, 1996). In fact, in a 2012 study, Dabney and colleagues (2012) found that some of the principal factors affecting university students' interest in STEM include high school OST science activities, middle school interest in science and mathematics, and gender. Dabney's study was limited by the inability to determine if the students' STEM interests were a result of, or a precursor to, participation in OST activities, leaving room for further research on the specific effects of OST activities at different ages.

In a further examination of the STEM gender gap, Hazari and colleagues (2013) tested five common hypotheses on the retention of female students' STEM career interests throughout high school and early college, concluding that the discussion of underrepresentation of women in science during high school science classes had a significant positive effect on the female students' persisting STEM interest. In light of this finding, the authors suggested that female STEM students are not in need of different classroom structures or more female role models, but rather that they need to be able to associate their personal identity with a STEM identity. This is supported by findings showing that women with higher gender rejection sensitivity (a measure of the tendency to perceive social-identity threat) experience larger self-reported instability in "gender-STEM compatibility" during their freshman (initial) year of college (Ahlqvist $e t$ al., 2013). Thus, there appears to be great potential to reduce the STEM gender gap if female students are able to reconcile their gender identity and their interest in STEM, as they may learn to do through out-of-school-time STEM activities.

It is noteworthy, however, that, among students in physics classrooms, the females were significantly less likely to report that the class focused on conceptual understanding, currently relevant science topics, or the benefits of becoming a physicist, although all of these factors positively affected the physics identities of male and female students alike (Hazari, Sonnert, Sadler, \& Shanahan, 2010). This difference in perception between male and female students inside the classroom is one reason why researchers have begun to shift their focus to OST activities, where students have an opportunity to cultivate their STEM identity independent of classroom factors. Furthermore, recent research shows that absolute levels of mathematics and science achievement in school are poor explanations for the persistent gender gap, because female students tend to have a higher mathematics and science GPA in high school than do male students, and that both males and females are taking more high school level mathematics and science courses than ever before (Riegle-Crumb et al., 2012; Shettle et al., 2007). For these reasons, our study sets out to examine the effects of out-of-school-time activities on students' persevering interest in astronomy careers, and to put them in relation to the effects of mathematics/science background and gender. The guiding research question is: what is the evolution of student interest in an astronomy career in the period between middle school and the beginning of college.

It is important to note that no study of this scale examining the effect of OST activities on astronomy career interest has been reported in the literature. The vast majority of recent publications have focused on classroom pedagogical theory, classroom activities, or student misconceptions, as summarized by Bailey and Slater (2005), Bishop (2002), and Lelliot and Rollnick (2009). In these publications, little to no attention is given to outside-of-school-time activities other than visiting planetaria (Tatge, et al., 2016). Furthermore, these studies do not examine the effect of student experiences on students' career intentions. Only sparse research has indirectly addressed this topic so far (Christensen, Knezeck, \& Tyler-Wood, 2014; Slater, 2010), and our investigation contributes to remedying this lacuna in astronomy education research.

\section{METHOD}

The data for this article are drawn from the "Outreach Programs and Science Career Intentions" (OPSCI) study $(\mathrm{n}=15,847)$, funded by the National Science Foundation (NSF \#1161052). They were collected through a large survey administered in the fall term of 2013 to incoming students at a sample of U.S. institutions of higher education that participated in the Science, Technology, Engineering, and Mathematics Talent Expansion Program (STEP) of the 
National Science Foundation. This program supported initiatives geared toward increasing the number of students receiving associate or baccalaureate degrees in the STEM fields. The survey was administered in freshman English courses, a typical general education requirement for all students - or in similar generally required courses - to gain a representative sample of both STEM and non-STEM students at each participating institution.

In the typical case, personalized recruitment emails were sent to the chairs of the English Department, specifically mentioning the STEP researcher involved at their university. Of the 150 institutions, 104 never responded to repeated inquiries. Of the 46 that responded, 27 (59\%) participated with at least one professor. This included 23 four-year institutions and 4 two-year institutions. Of the 535 instructors who initially agreed to administer the survey, 414 instructors (77\%) followed through, returning 15,847 completed student surveys. The surveys were administered in hardcopy during class time so that student participation was close to $100 \%$.

The questions of the OPSCI survey were to a considerable portion identical with the questions that had been previously developed and successfully used in an earlier study titled "Persistence Research in Science and Engineering" (PRiSE; NSF \#0624444). Other questions were created specifically for the OPSCI survey by the project team. The OPSCI survey was pilot tested with students at a southern university where, in addition, test-retest reliability of the survey was established by administering the survey to 57 students at that same university twice, in an interval of about two weeks. For continuous variables, the Pearson correlation coefficient between the test and retest answers served as a measure of reliability; for categorical variables, Cohen's kappa was used. The overall means were 0.73 for the correlation coefficients, and 0.59 for the Cohen's kappas. A copy of the relevant questions from the OPSCI survey is shown in Appendix B.

Our analyses of the OPSCI data concentrated on students' reported career interests and their interest/participation in OST activities (survey questions shown in Appendix B). Students were asked to indicate any and all career interests they had in middle school (MS), at the beginning of high school (BHS), the end of high school (EHS), and in college $(\mathrm{Col})$. Note that careers in medicine and health are not included within the umbrella term "STEM" for the purposes of this study, but will be addressed as "STEM-related" fields. This decision was based on the NSF definitions of STEM and STEM-related fields.

On the OPSCI survey, students also indicated interest and participation in OST activities related to STEM fields. From a given list, students could select as many activities as they wanted for the following stages in their education: kindergarten through fourth grade, fifth through eighth grade, ninth, tenth, eleventh, and twelfth grades. Regarding gender, $50.7 \%$ of respondents self-identified as female, $38.7 \%$ self-identified as male, and $10.6 \%$ did not specify.

Of particular interest is if the OPSCI sample contained a sufficient number of aspiring astronomers, as measured against national averages. For an approximate comparison, we used national data about freshmen's intended majors from the American Freshman Survey of 2013 (Eagan, Lozano, Hurtado, \& Case, 2013). In that survey, 0.1\% of freshmen reported an intended major in astronomy and astrophysics, whereas, in the OPSCI sample, $0.9 \%$ of the students planned a career in astronomy. Likewise, for most STEM fields, the percentages of OPSCI participants reporting a career interest were higher than the corresponding percentages of freshmen's intended majors found in the American Freshman Survey. (An exception was biology where the career interest was lower than the intended major, probably because an intended major in biology often goes with a career interest in medicine or health.) On the whole, thus, the institutions participating in the OPSCI study appeared to have a somewhat STEM-heavy student population, which might be explained at least partly by the fact that they were all participants of the Science, Technology, Engineering, and Mathematics Talent Expansion Program (STEP) of the National Science Foundation. In particular, aspiring astronomers were well represented in the OPSCI sample, and their numbers were large enough to allow statistical analyses of their career interests.

\section{RESULTS}

\section{Descriptive Statistics}

We first examined the overall trends of interest in any given career over time, with respect to gender. As shown in Table 1, astronomy interest experiences the most extreme and constant exponential decrease of all fields examined. 
Female students have lower interest at every phase of education, and the decrease in astronomy interest is slightly stronger for females. However, after performing a t-test on the slopes of the male and female regression lines, the null hypothesis could not be rejected, thus it cannot be concluded that male and female students have a significantly different decrease in interest during this time.

Table 1. Percent of students interested in specified careers in middle school (MS), beginning of high school (BHS), end of high school (EHS), and college, grouped by males and females

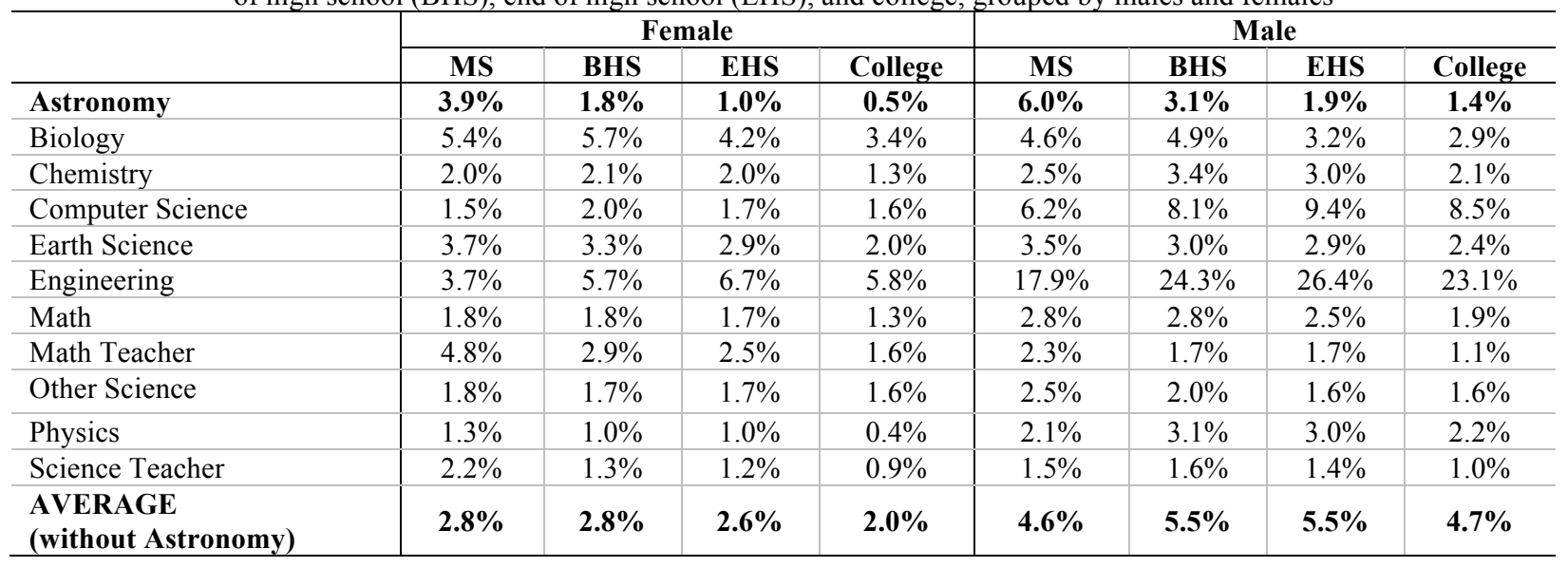

Having looked at the development of career interests in terms of group-level percentages, we now turn to a more fine grained examination of the trajectories of students' career intentions. A graphical analysis was conducted in the form of inflow and outflow mapping to examine what happens to the students who leave astronomy. Do they remain interested in STEM, or abandon their interest in science completely? This analysis is shown in the Sankey diagram in Figure 1, which depicts the flows of students into and out of astronomy career interest across various educational stages. Tables corresponding to Figure 1 are shown in Appendix A.

Reading the diagram in Figure 1 from left to right, lines flowing from astronomy to other fields are "outflows." Lines flowing from other fields into astronomy are "inflows" and show the fields astronomy-interested students come from. In this diagram, we see the overall flow of students into astronomy decrease notably as students get older. The figure also indicates that most of the students leaving astronomy do so in favor of other STEM fields, suggesting that astronomy may function as a feeder into other STEM disciplines. That is good news: even though astronomy loses student interest at every educational stage, a majority of those students leave astronomy in favor of another STEM field. 
Figure 1. Astronomy inflow \& outflow diagram for all students (male and female data combined). Path color-coding is as follows: black (top) indicates students who retain interest in astronomy, red (second) indicates students who move between other STEM fields and astronomy, green (third) indicates students who move between STEM-related fields and astronomy, and blue (bottom) indicates the paths between non-STEM fields and astronomy.

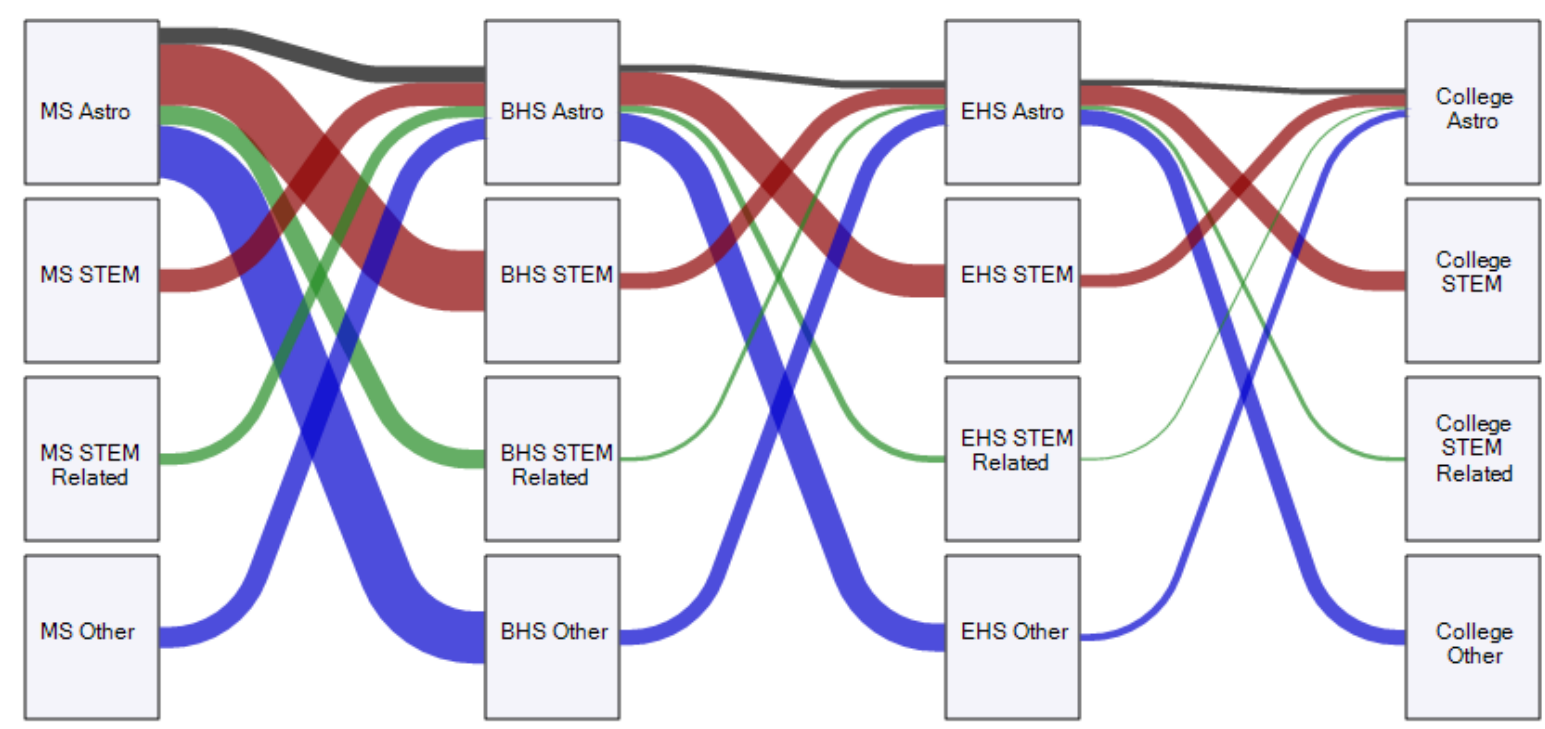

We also examined these flows for male and female students separately. The patterns of student inflow into astronomy career interest are largely identical for males and females. The outflows, however, revealed that a higher percentage of males flow from astronomy into other STEM fields, and a higher percentage of females flow from astronomy to non-STEM fields. For example, between the beginning of high school and the end of high school, $29 \%$ of females and $50 \%$ of males initially interested in astronomy will be interested in STEM (outside of astronomy), while $44 \%$ of females and $30 \%$ of males initially interested in astronomy end up interested in non-STEM fields. This pattern holds across all educational stages.

Students were also asked to identify which 13 listed outside-of-school-time (OST) activities they experienced over the course of their education. The percentages of student interest in each activity can be seen in Table 2. We reduced these 13 activities to 9 variables through factor analysis. Factor analysis expresses the variability of a large number of correlated variables (the 13 OST activities in the initial survey) in terms of a smaller number of variables (the 9 OST activity combinations used in our models). This is an essential step before creating a regression model, because the inclusion of highly correlated variables creates collinearity issues and inhibits accurate estimates.

Table 2. Percent of students interested in each OST activity shown for all participants, males, and females. Bold text indicates the gender that showed a significantly $(\mathrm{p}<0.05)$ higher participation rate.

\begin{tabular}{l|c|c|c}
\hline & \% of All Students & \% of Males & \% of Females \\
\hline Animals & $61.3 \%$ & $62.1 \%$ & $\mathbf{6 5 . 7 \%}$ \\
\hline Chemistry & $45.1 \%$ & $47.7 \%$ & $46.6 \%$ \\
\hline Science/Math Competitions & $32.6 \%$ & $\mathbf{3 6 . 0} \%$ & $32.3 \%$ \\
\hline Observe Stars & $43.2 \%$ & $45.4 \%$ & $44.7 \%$ \\
\hline Plants & $59.6 \%$ & $55.2 \%$ & $\mathbf{6 7 . 9 \%}$ \\
\hline Programming & $25.8 \%$ & $\mathbf{3 2 . 1 \%}$ & $22.7 \%$ \\
\hline Read/Watch Non-Fiction Science & $48.0 \%$ & $\mathbf{5 5 . 0 \%}$ & $46.1 \%$ \\
\hline Read/Watch SciFi & $54.6 \%$ & $\mathbf{6 3 . 9 \%}$ & $51.6 \%$ \\
\hline Science Groups/Clubs/Camps & $33.3 \%$ & $34.5 \%$ & $35.0 \%$ \\
\hline Talk About Science & $48.8 \%$ & $\mathbf{5 3 . 6 \%}$ & $49.0 \%$ \\
\hline Tinker with Electronics & $48.6 \%$ & $\mathbf{6 4 . 4 \%}$ & $39.3 \%$ \\
\hline Tinker with Mechanics & $50.9 \%$ & $\mathbf{6 5 . 6 \%}$ & $42.9 \%$ \\
\hline Computer/Video Games & $64.5 \%$ & $\mathbf{8 0 . 1 \%}$ & $57.1 \%$ \\
\hline
\end{tabular}


The resulting OST variables are as follows: taking care of animals; tinkering with mechanical and/or electrical devices; engaging in chemistry \& planting seeds/collecting things in nature; participation in science groups, clubs, camps, and/or competitions; writing computer programs and/or web pages; reading/watching non-fiction science \& SciFi; playing computer or video games; talking to family and peers about science; and observing stars. The OST activity "observing stars" was not included in the factor analysis as it is directly related to astronomy and so should not be combined with other activities for this analysis. For the purposes of our study, these OST categories were operationalized as dummy variables indicating whether a student participated in the activities at any point during their education. For OST activities that were combined via factor analysis (such as engaging in chemistry \& planting seeds/collecting things in nature), the variables were operationalized as dummy variables that indicated if the student had ever participated in any of these activities. These OST variables will come into play as predictors in the statistical modeling of astronomy career interest.

\section{STEM Inflows}

Building on the broad picture provided by our Sankey diagram (Figure 1), we undertook a more detailed analysis focused on the interval between the beginning and end of high school and on the common paths students take during that time on the way to a career interest in astronomy or STEM in general.

Table 3 and Figure 2 show the percentage of students interested in pursuing a STEM career at the end of high school (EHS), given a particular interest at the beginning of high school (BHS). We see that female STEM interest is lower than male STEM interest across the board. Furthermore, of students interested in astronomy at the beginning of high school, the percentage of males who maintain a career interest in STEM is $22 \%$ higher than the corresponding percentage of females. This is the second largest gender gap out of all BHS STEM interests. The largest gender gap occurs in computer science, where the percentage of males who stay in STEM is $23 \%$ higher than the percentage of females.

We also analyzed the likelihood of a student becoming interested in astronomy specifically, given a particular BHS interest (Table 4, Figure 3). In this graph, we see that an astronomy interest has a relatively low retention rate $(\sim 20 \%)$, and that the field producing the second most astronomy-interested students is physics at only $\sim 12 \%$. This figure combines several careers into broader categories (STEM, STEM-Related, and Other) to keep error bars reasonably small, since relatively few students in our sample were interested in astronomy at EHS (227).

Table 3. Percent of students interested in any STEM career at EHS, given that they were interested in these specified careers at BHS, sorted by male student interest.

\begin{tabular}{|c|c|c|c|}
\hline & & Males & Females \\
\hline \multirow[t]{11}{*}{ STEM } & Physics & $76.8 \%$ & $71.1 \%$ \\
\hline & Math & $76.6 \%$ & $59.0 \%$ \\
\hline & Science Teacher & $76.2 \%$ & $61.4 \%$ \\
\hline & Astronomy & $76.1 \%$ & $53.7 \%$ \\
\hline & Other Science & $76.0 \%$ & $64.7 \%$ \\
\hline & Chemistry & $75.0 \%$ & $56.2 \%$ \\
\hline & Earth Science & $73.8 \%$ & $56.7 \%$ \\
\hline & Engineering & $73.4 \%$ & $58.4 \%$ \\
\hline & Biology & $71.8 \%$ & $53.6 \%$ \\
\hline & Computer Science & $71.0 \%$ & $47.8 \%$ \\
\hline & Math Teacher & $67.9 \%$ & $52.2 \%$ \\
\hline \multirow[t]{10}{*}{ Non-STEM } & Social Science & $43.4 \%$ & $16.6 \%$ \\
\hline & Law & $36.3 \%$ & $20.2 \%$ \\
\hline & Health & $36.2 \%$ & $15.3 \%$ \\
\hline & Teacher & $36.0 \%$ & $14.4 \%$ \\
\hline & English & $36.0 \%$ & $19.0 \%$ \\
\hline & Art & $35.4 \%$ & $18.3 \%$ \\
\hline & Sports & $33.9 \%$ & $22.3 \%$ \\
\hline & Medicine & $32.8 \%$ & $18.0 \%$ \\
\hline & Business & $31.0 \%$ & $19.5 \%$ \\
\hline & Other & $26.8 \%$ & $16.9 \%$ \\
\hline
\end{tabular}


Figure 2. Percent of students interested in STEM at EHS, given that they were interested in the career specified along the $x$-axis at BHS. Horizontal black lines represent the average values for percent of students with EHS STEM interest, divided into four categories: females with BHS non-STEM interest, males with BHS non-STEM interest, females with BHS STEM interest, and males with BHS STEM interest. Error bars indicate 1 standard error.

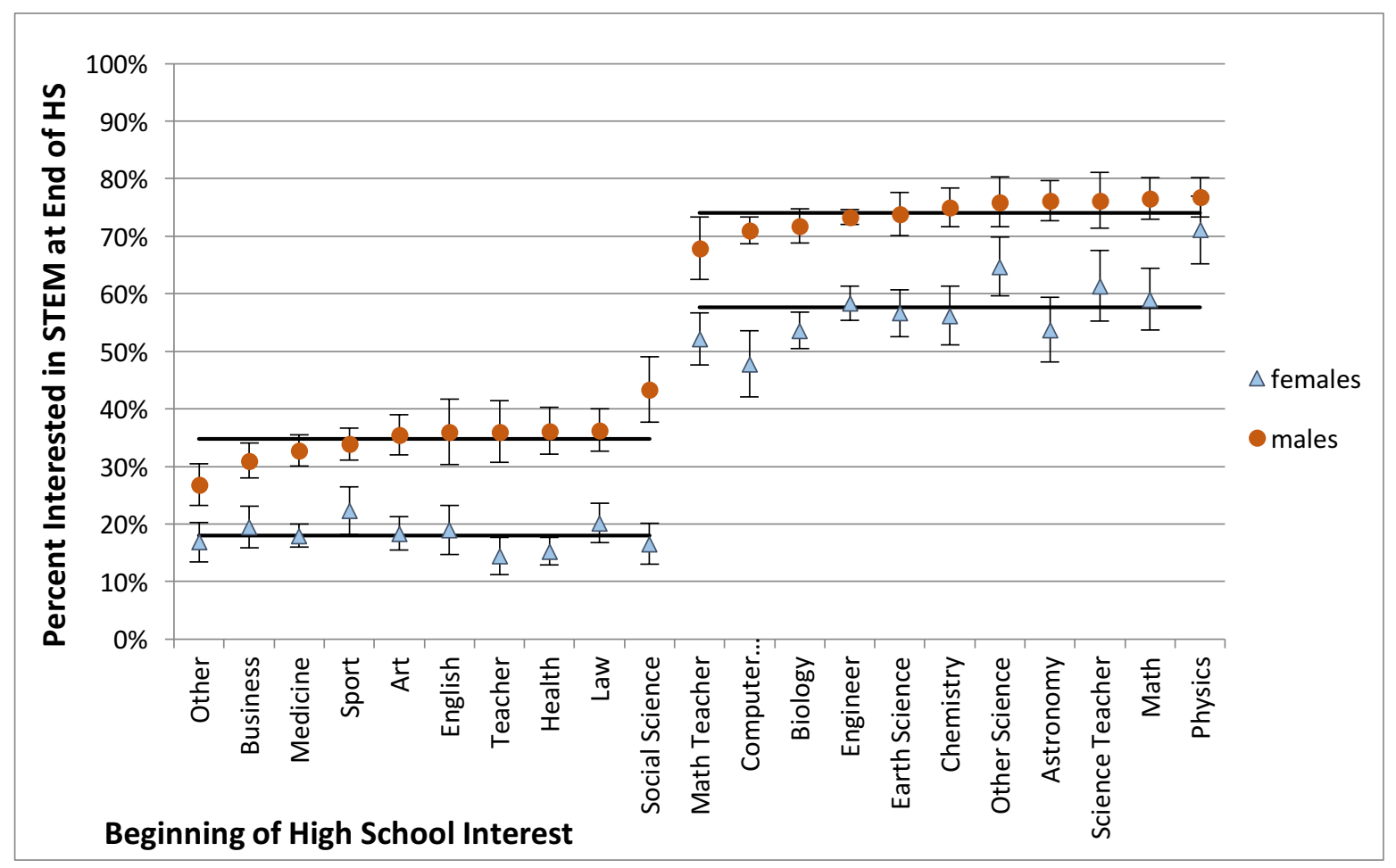

Table 4. Percent of students interested in astronomy at EHS, given that they were interested in a career within the specified groups at BHS.

\begin{tabular}{l|c|c}
\hline & Male & Female \\
\hline Astronomy & $21.8 \%$ & $19.0 \%$ \\
\hline Physics & $9.6 \%$ & $14.5 \%$ \\
\hline Other STEM & $2.5 \%$ & $2.4 \%$ \\
\hline Non-STEM & $2.3 \%$ & $1.1 \%$ \\
\hline STEM-related & $1.8 \%$ & $0.8 \%$ \\
\hline
\end{tabular}


Figure 3. Percent of students interested in astronomy at EHS, given that they were interested in the career specified along the $\mathrm{x}-$ axis at BHS. BHS interests are grouped by major category, with Astronomy and Physics included as separate fields. Male data points are shown in red, female data points are shown in blue. Error bars indicate 1 standard error.

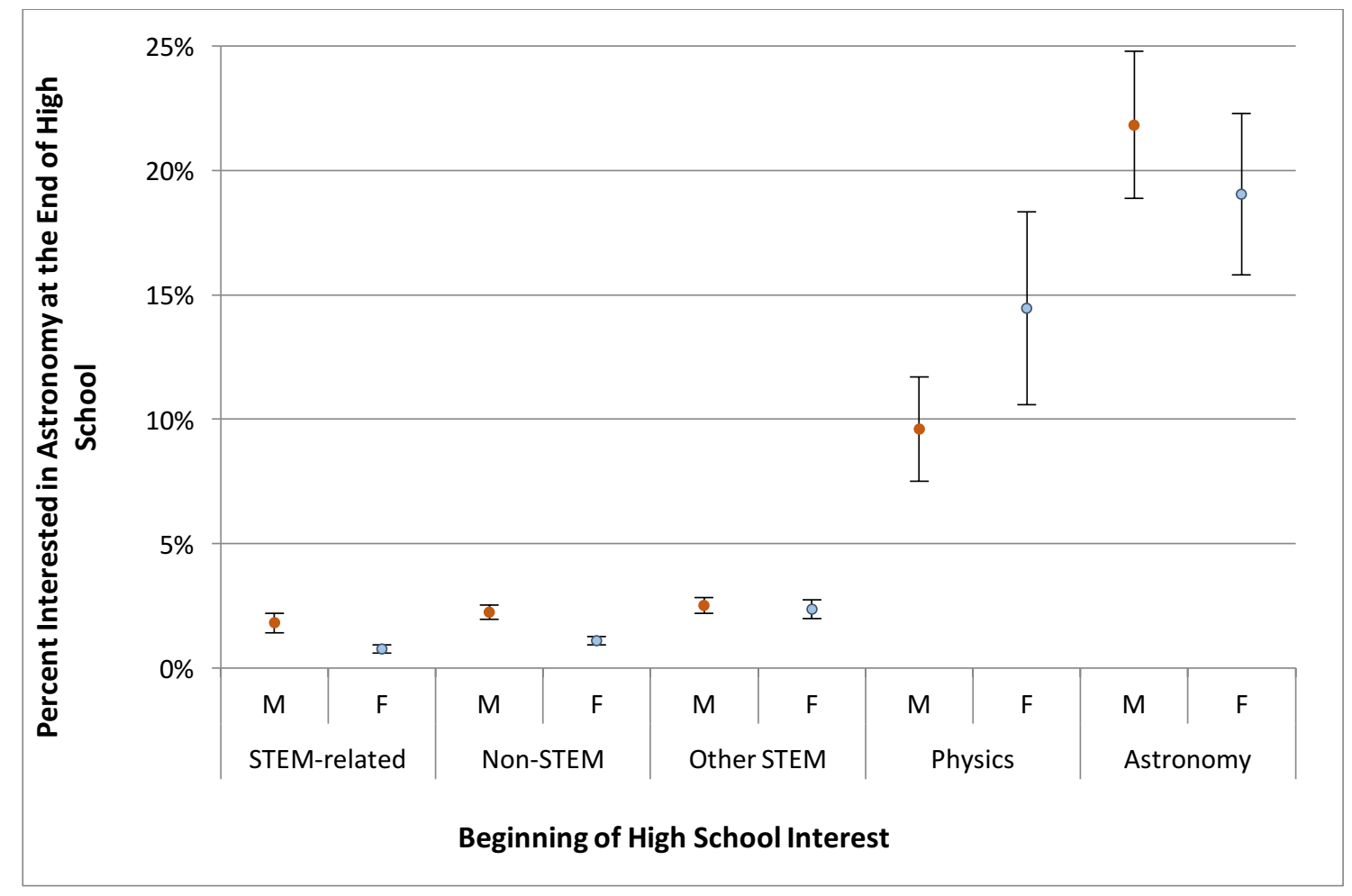

\section{Statistical Models}

We used logistic regression to model factors that could influence EHS astronomy interest for male and female students (Tables 5 \& 6). Model 1 incorporates some demographic control variables that are commonly used in this kind of study, such as the students' SAT mathematics scores ${ }^{1}$, if the students took physics, and if the students took calculus (Sadler et al., 2012). In Model 2, we also examined effects from the 9 OST factors, as combined via factor analysis. Model 3, our final main effects model, contains only the significant predictors of end of high school astronomy career interest, as found by stepwise elimination. Finally, Model 4 (shown in Table 6) incorporates the only significant interaction between two independent variables: the students' gender and if they observed stars outside of school. In all four of these models, the logistic regression coefficients are transformed into odds ratios for ease of interpretation. Odds ratios compare the relative odds of an outcome between different states of an independent variable (for instance, the odds of an astronomy career interest among males, compared with the odds of an astronomy career interest among females). Note that odds ratios for the main effects of gender and observing stars cannot be interpreted directly from Model 4, as they are affected by the interaction.

The results of Model 3 suggest that students who are interested in BHS astronomy have 20 times higher odds of EHS astronomy interest than those who are not. The odds of a student with BHS STEM interest having EHS astronomy interest are almost twice as high as those of a student not interested in BHS STEM (1.8:1). Students who like to observe stars have 2:1 odds in favor of EHS astronomy career interest, compared with those who do not, students who tinker have 1.4:1 higher odds in favor of EHS astronomy interest, and students who read/watch non-fiction science or sci-fi have 1.5:1 higher odds for the same. Students who take care of animals as a hobby have 1.8 times worse odds

\footnotetext{
${ }^{1}$ For those students who reported an ACT score rather than an SAT score, this score was converted to the SAT scale, using the SAT-ACT concordance published by the College Board Office of Research and Development (1999).
} 
of having EHS astronomy interest than those who do not. It should be noted that there is not a significant difference in the odds of EHS astronomy career interest based on gender alone according to Model 3.

We also investigated potential interactions between explanatory variables, focusing our investigation on the interaction between gender and other variables in the model, and on the interaction between significant OST activities and all other variables; but ultimately the only significant interaction effect occurred between gender and observing stars, as seen in Model 4 (Table 6). The odds ratios corresponding to this interaction are shown numerically in Table 7 and graphically in Figure 4. Males who observe stars have 1.6 times greater odds of EHS astronomy interest than males who do not, and females who observe stars have 3.7 times higher odds of EHS astronomy interest than females who do not. The odds ratio for the female students (between those who observe and those who do not) is therefore more than twice the odds ratio for the male students. This suggests that observing stars can work to bridge the gender gap in astronomy interest, as the career interest of females is much more sensitive to observing stars than that of males. It should be noted that the probabilities shown in Table 7 are all still remarkably low $(<1 \%)$ due to the overall attrition of students from astronomy.

Table 5. Results of logistic regression main effects models predicting EHS astronomy career interest. Demographic control variables include MS interest in astronomy, BHS interest in astronomy, BHS interest in STEM (other than astronomy), if the student took calculus, if they took physics, their SAT mathematics score, and gender $(1=$ male, $0=$ female). Model 2 also includes explanatory variables from OST activities. Model 3 shows only the final significant variables. Results are given in odds ratios.

\begin{tabular}{l|c|c|c}
\hline \multicolumn{1}{c}{ Variable } & Model 1 - Demographics & Model 2 - with OST & Model 3 - Significant vars \\
\hline MS astronomy & 1.706 & 1.374 & $20.389^{* * *}$ \\
\hline BHS astronomy & $15.031^{* * *}$ & $12.569^{* * *}$ & $1.844^{* * *}$ \\
\hline BHS STEM & $1.767^{*}$ & $1.743^{*}$ & \\
\hline Took calculus & 3.120 & 1.384 & \\
\hline Took physics & 1.071 & 1.014 & \\
\hline SAT math (per 100 pts) & 0.999 & 0.999 & $1.765^{\dagger * * *}$ \\
\hline Gender & 1.203 & 1.130 & \\
\hline Animals & & 0.694 & \\
\hline Chemistry/plants & & 0.800 & $1.530^{*}$ \\
\hline Competitions/groups & & 1.355 & \\
\hline Video games & & 0.913 & \\
\hline Non-fiction science/Sci-Fi & & $2.123^{*}$ & $1.432^{*}$ \\
\hline Programming & & 0.754 & $2.073^{* * *}$ \\
\hline Talking about science & 14,348 & 1.522 & 14,348 \\
\hline Tinkering & 0.138 & 1.335 & 0.179 \\
\hline Observing stars & & $2.715^{* * *}$ & \\
\hline$N$ & & 14,348 & 0.175 \\
\hline Pseudo $R^{2}$ & & 0.175 & \\
\hline
\end{tabular}

${ }^{\dagger}$ indicates an inverted odds ratio, as students who take care of animals outside of school have 1.8 times lower odds of EHS astronomy career interest.

Table 6. Results of the final logistic regression model, including only significant variables and the interaction effect between gender $($ male $=1$, female $=0)$ and observing stars.

\begin{tabular}{l|c}
\hline \multicolumn{1}{c}{ Variable } & Model 4 - Interaction \\
\hline BHS astronomy & $18.3^{* * *}$ \\
\hline BHS STEM & $1.8^{* * *}$ \\
\hline Animals & $0.7^{*}$ \\
\hline Non-fiction science / Sci-Fi & $1.8^{* *}$ \\
\hline Observing stars & $3.7^{* * *}$ \\
Gender & $2.5^{* *}$ \\
\hline Gender $*$ Observing stars & $*$ \\
\hline$N$ & 14,348 \\
\hline$P$ Peudo $R^{2}$ & 0.1747 \\
\hline
\end{tabular}


Table 7. Probability, relative odds, and odds ratios for student interest in an astronomy career at EHS as based on the interaction effect between gender and observing stars found through logistic regression.

\begin{tabular}{|c|c|c|c|}
\hline & & Male & Female \\
\hline \multirow{2}{*}{ Probability } & Observed stars & $1.0 \%$ & $0.9 \%$ \\
\hline & Did not observe stars & $0.6 \%$ & $0.2 \%$ \\
\hline \multirow[t]{2}{*}{ Relative Odds } & Observed stars & 4.1 & 3.7 \\
\hline & Did not observe stars & 2.5 & 1.0 \\
\hline Odds Ratio & Observed / Did not observe & 1.6 & 3.7 \\
\hline
\end{tabular}

Figure 4. Probability of student interest in an astronomy career at EHS for the interaction effect between gender and observing stars. Error bars indicate 1 standard error of the interaction.

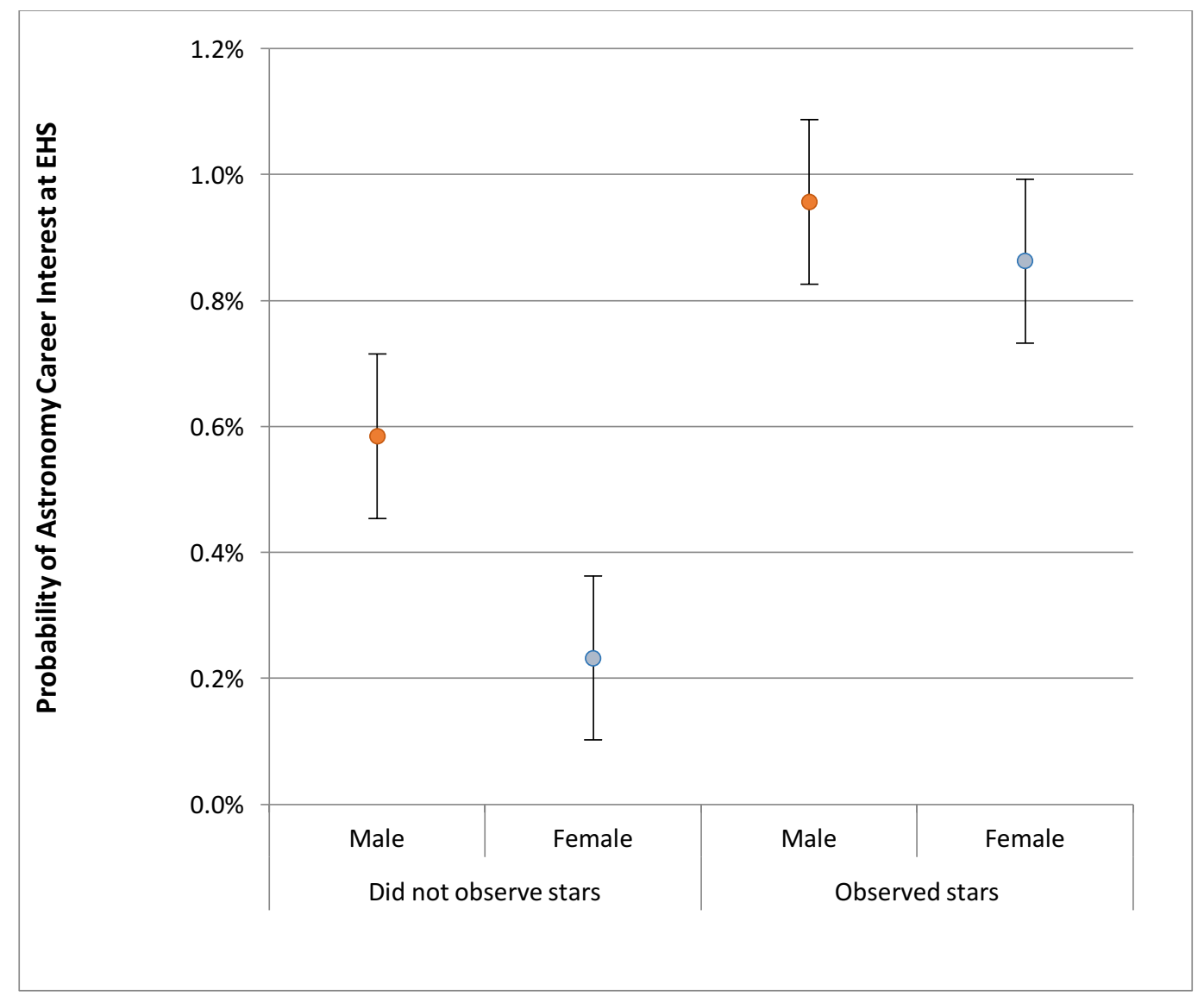

\section{DISCUSSION}

Our findings reveal uncharted information about the factors that affect the retention of astronomy students and the evolution of their career interests. In Figure 2, we see that STEM interest is lower across the board for female students compared to male students, confirming that, despite progress in recent years, there is still a prominent gender gap in STEM fields during students' secondary education. We also confirm the findings of Sadler et al. (2012), who observed the largest gender gaps to occur in astronomy and computer science. Furthermore, the field of astronomy experiences the most extreme and constant decrease in student interest of all fields spanning middle school to college, as shown in Table 1. 
Through Sankey diagram analysis, which depicts inflows and outflows of astronomy students, as shown in Figure 1, we found that, for male students, and to a lesser extent for females, there is a voluminous outflow from astronomy into other STEM fields. A lower percentage of women than men remain in STEM, instead often moving into STEMrelated (Health/Medicine) or non-STEM disciplines. These findings give credence to the often-used "leaky pipeline" metaphor, which asserts that many students, particularly females, begin their education with interest in STEM but are lost at various stages along the way. However, to some extent, astronomy counteracts this phenomenon by providing a pathway to hook students into other STEM fields.

Through statistical modeling, we found that several OST activities have significant impact on students' career choices. Specifically, we saw that students who spend extracurricular time tinkering with mechanical or electrical devices, or reading/watching non-fiction science or sci-fi have increased odds of an astronomy career interest at the end of high school, regardless of gender. Observing stars outside of school is also associated with an increase in the odds of an astronomy career interest, with females experiencing an increase in odds that is more than twice as large as the one experienced by males. It is noteworthy that our final main effects model (Model 3 - Table 5) does not include control variables for the students' physics and mathematics background or their SAT mathematics score (which were found non-significant), even though such factors had previously proven significant in the pursuit of other STEM fields (such as physics) in the literature. This result supports findings that suggest that academic predictors do not fully explain today's STEM gender gap, as males and females currently have comparable high school STEM preparation.

The interaction between gender and observing stars is also interesting in light of recent findings which state that female students often feel less welcome in science-related groups and clubs. This creates a tension between the benefits of OST science for girls and the barriers deterring their participation, and raises several questions: if students receive enough encouragement to engage in OST science activities, will the rate of STEM participation increase? How much benefit will this confer towards increasing STEM interest in general and bridging the STEM gender gap? Moreover, of the three significant, positive OST predictors of EHS astronomy career interest, observing stars has the closest and most obvious connection to astronomy, while tinkering and reading/watching science are associated more loosely. In the case of reading and watching science-related materials, however, this positive relationship may be traceable back to the dominance of astronomy in pop-culture science: people like to hear about black holes, life on other planets, space missions, the Big Bang, and similar topics that dominate mass-media science coverage. The tinkering connection to astronomy may be effected through the building of telescopes or rocket-type devices.

Past research has found OST science activities to be a key factor for university students' career interest in STEM, but has been limited by the inability to discern if OST activities were a result of, or precursor to, STEM interest. Even though the precise time sequence of OST activities and astronomy career interest could not be ascertained through our data, we could at least determine that in some cases students who had not been interested in astronomy at the beginning of high school subsequently engaged in astronomy-related activities during high school and then reported a career interest in astronomy at the end of high school, while in other cases, the OST activities followed an interest already established at the beginning of high school. These two scenarios occurred with approximately equal frequency: of students who expressed interest in an astronomy career and observed stars at any point, $49 \%$ were observing stars before they considered an astronomy career, while $43 \%$ were interested in an astronomy career before beginning to observe stars recreationally. We cannot confirm that these sequences are causal, but we do see that observing stars is associated with a significant increase in the odds of EHS astronomy interest, as shown by Models 3 and 4 (Tables 5 $\& 6$, respectively).

Furthermore, our data suggest that the three OST activities that acted as positive predictors for EHS astronomy interest (observing stars, tinkering, and reading/watching non-fiction science and science fiction-SciFi) have equal influence on students who were not interested in astronomy careers at BHS and students who were (as the absence of an interaction between BHS interest and OST activities suggests).

The data used in this study, as obtained through the OPSCI survey $(n=15,848)$, included responses from hundreds of students interested in astronomy. That being said, this number is still much smaller than the number of surveyed students interested in other STEM fields. Had we been able to survey a larger sample of astronomy students, we might have been able to conduct a more detailed analysis on the difference between patterns experienced by male and female students while keeping error margins appropriately small. For example, it may be interesting in the future to expand 
upon Figure 4 to show the percentages of male vs. female students interested in astronomy at the end of high school for a more detailed range of specific beginning of high school interests.

We have seen that certain OST activities are better predictors of astronomy career interest than are commonly studied academic predictors, such as SAT mathematics score, if the student has taken physics, and if the student has taken calculus. This is noteworthy both in light of past research - which has shown such predictors to be significant for related fields (Sadler et al., 2012) - and in light of a common hypothesis among astronomy faculty that astronomy drop-outs did not previously understand the depth of scientific and mathematical understanding required to pursue astronomy. Future investigations may take interest in a detailed analysis of how the influences of OST activities and academic preparation compare for other STEM disciplines, particularly physics, which is an adjacent field to astronomy. Additionally, future research may wish to examine young students' early notions of what an astronomy career entails in terms of required scientific and mathematical knowledge. Do students drop out when they realize they cannot earn a bachelor's degree simply by observing stars?

Our research focused on the transition between the beginning and end of high school. For a more comprehensive view of how astronomy career interest develops, it might be worthwhile to specifically look at STEM-related OST activities in middle school and examine their potentially lasting effects. This would require longitudinal hierarchical modeling, which we did not engage in for this study, but which could be a promising avenue for future work.

Finally, while we were able to draw several conclusions regarding students' career intentions, these intentions are limited by the age of the survey participants - college freshmen. In order to truly understand the effects of these OST activities on career trajectories, future research would need to track these students through to at least the beginning of their professional careers in order to conclusively remark on the relationship between OST activities and students' actual careers.

\section{CONCLUSION}

In this study, which controlled for interest at the beginning of high school (BHS) and other background variables, we have demonstrated that students who engage in certain science-related out-of-school-time (OST) activities have higher odds for a career interest in astronomy at the end of high school (EHS) than do students who do not participate in those activities. Most notably, students who observe stars, tinker with mechanical or electrical devices, or read/watch science-related materials extracurricularly have improved odds of an astronomy career interest at the end of high school. Furthermore, there is an interaction effect between gender and observing stars, such that, for female students, observing stars boosts the odds of an EHS astronomy interest more strongly than it does for male students. This has important implications for an implementable change. The presence of after-school programs and clubs geared towards observing stars might improve students' - and especially girls' - chances of pursuing astronomy at the end of high school. However, research has shown that one major barrier in elevating girls' physics identity is that female students tend to feel generally less welcome in science-related OST clubs and activities, compared with males (Sadler et al., 2012). It is therefore important that astronomy programs (clubs, camps, one-night events) strive to encourage female student enrollment. This may greatly accelerate girls' interest in astronomy, making their odds of pursuing astronomy comparable to those of the boys.

This conclusion brings light to serious problems with the current climate of male- and female-oriented OST activities. We see evidence of preconceived notions that science is a masculine field emerging even in single-sex OST activities not specifically related to science, such as the Boy Scouts and Girl Scouts of America. In these clubs, subtle descriptive differences trigger, or reinforce, the gendering of certain subjects (Denny, 2011; Sadler et al., 2012). The Boy Scouts tend to present badges with career-oriented or technical wording, whereas the Girl Scout badges have more whimsical connotations: "Environmental Science" for the Boy Scouts becomes "Flowers" for the Girl Scouts, "Oceanography" becomes "Water", and - as relevant to our research - "Astronomy" becomes "Sky" (Boy Scouts of America, 2014; Girl Scouts of America, 2014). This gendering of science related subjects is problematic in light of our results, and further emphasizes the need for intentionally female-inclusive STEM OST activities.

There is great potential benefit to be gained by female students who choose to participate in OST activities such as those, and in some cases an even greater benefit than their male counterparts would receive. With this in mind, it is 
up to educators and families to encourage female participation in these activities in order to work towards bridging the gender gap in astronomy career intentions.

\section{ACKNOWLEDGMENTS}

This work was supported by the National Science Foundation (grant number 1161052). Any opinions, findings, and conclusions in this article are the authors' and do not necessarily reflect the views of the National Science Foundation. Without the excellent contributions of many people, the OPSCI project would not have been possible. We thank the members of the OPSCI team: Wendy Berland, Zahra Hazari, Tyler Scott, and Annette Trenga. We would also like to thank several STEM educators and researchers who provided advice or counsel on this project: Charles Alcock Rocco Cieri, Katherine Dabney, Connie Della-Piana, Robert Andrew Kolvoord, Chandra Muller, Matthew Ohland, Harriet Page, Barbara J. Speziale, and Christos Zahopoulos. Last but not least, we are grateful to the many college English professors and their students who gave up a portion of a class to provide data.

\section{AUTHOR BIOGRAPHIES}

Zoey Bergstrom, B.S. is member of the Harvard University class of 2015 with an undergraduate major in Astrophysics \& Physics. She now works for uAspire, a national non-profit based in Boston that strives to make a postsecondary education accessible and affordable to all students. She is interested in pursuing a career in science education in the future. Her email address is: zabergstrom@gmail.com

Philip Sadler, Ed.D. directs the Science Education Department at the Harvard-Smithsonian Center for Astrophysics' and is the F.W. Wright Senior Lecturer in Astronomy. He holds a B.S. in Physics from MIT and an Ed.M. and Ed.D. from Harvard. He has taught middle school mathematics, science, and engineering, as well as undergraduate astronomy and graduate teaching courses. Dr. Sadler has won the JRST Award, the AIP's Computers in Physics Prize, the AAS Education Prize, and the AAPT's Millikan Medal. Curricula and materials developed by Dr. Sadler, including the Starlab portable planetarium, are used by an estimated fifteen million students yearly.

Gerhard Sonnert, Ph.D. is a research associate in the Science Education Department at the Harvard-Smithsonian Center for Astrophysics and an associate of the Harvard Physics Department. He holds a doctorate in sociology from the University of Erlangen and an M.P.A. from Harvard University. He has conducted several large empirical studies in STEM education, and particularly about gender aspects in STEM (Gender Differences in Science Careers and Who Succeeds in Science?: The Gender Dimension, both 1995, with G. Holton). Other interests include science policy (Ivory Bridges: Connecting Science and Society, 2002, with G. Holton), and history of science (Einstein and Culture, 2005).

\section{REFERENCES}

Ahlqvist, S., London, B., \& Rosenthal, L. (2013). Unstable identity compatibility: How gender rejection sensitivity undermines the success of women in science, technology, engineering, and mathematics fields. Psychological Science, 24(9), 644652.

Bailey, J. M., \& Slater, T. F. (2005). Resource letter AER-1: Astronomy education research. American Journal of Physics, 73(8), 677-685.

Bailey, J. M., Coble, K., Cochran, G., Larrieu, D., Sanchez, R., \& Cominsky, L. R. (2012). A multi-institutional investigation of students' preinstructional ideas about cosmology. Astronomy Education Review, 11(1), 010302.

Barlow, N., Cordova, F. A., Bahcall, J., Price, J., Eastwood, K., Bahcall, N., ... \& Trimble, V. (1992). Women in astronomy: A sampler of issues and ideas. Mercury, 21, 27-36.

Bayer Corp. (2012). Bayer facts of science education XV: A view from the gatekeepers-STEM department chairs at America's top 200 research universities on female and underrepresented minority undergraduate STEM students. Journal of Science Education and Technology, 21(3), 317-324. Retrieved March 1, 2015, from www.jstor.org

Bergin, D. A. (1996). Adolescents' out-of-school learning strategies. The Journal of Experimental Education, 64(4), $309-323$.

Bishop, J. E. (2002). Pre-college astronomy education in the United States in the twentieth century. Information Handling in Astronomy-Historical Vistas, 207-231.

Boy Scouts of America. (2014). Merit Badges. Retrieved from http://www.scouting.org/meritbadges.aspx 
Bureau of Labor Statistics. (2015). STEM crisis or STEM surplus? Yes and yes: Monthly Labor Review: U.S. Bureau of Labor Statistics. Retrieved May 3, 2016, from www.bls.gov/opub/mlr/2015/article/stem-crisi-or-stem-surplus-yes-andyes.htm.

Cheryan, S., Plaut, V. C., Davies, P. G., \& Steele, C. M. (2009). Ambient belonging: How stereotypical cues impact gender participation in computer science. Journal of Personality and Social Psychology, 97(6), 1045-1060.

Christensen, R., Knezek, G., \& Tyler-Wood, T. (2014). Longitudinal analysis of cognitive constructs fostered by STEM activities for middle school students. Knowledge Management \& E-Learning, 6(2), 103-122.

College Board Office of Research and Development (1999). Concordance between SAT I and ACT scores for individual students (Report RN-07, June 1999). New York: College Board.

Dabney, K. P., Tai, R. H., Almarode, J. T., Miller-Friedmann, J. L., Sonnert, G., Sadler, P. M., \& Hazari, Z. (2012). Out-ofschool time science activities and their association with career interest in STEM. International Journal of Science Education, Part B, 2(1), 63-79.

Dar-Nimrod, I., \& Heine, S. J. (2006). Exposure to scientific theories affects women's math performance. Science, 314(5798), 435-435.

Denny, K. E. (2011). Gender in context, content, and approach: Comparing gender messages in Girl Scout and Boy Scout handbooks. Gender \& Society, 25(1), 27-47.

Eagan, J., Lozano, J. B., Hurtado, S., \& Case, M. H. (2013). The American Freshman: National Norms Fall 2013. Los Angeles: Higher Education Research Institute, UCLA. Retrieved May 11, 2016, from http://www.heri.ucla.edu/monographs/theamericanfreshman2013.pdf.

Fisher, A., Margolis, J., \& Miller, F. (1997, March). Undergraduate women in computer science: experience, motivation and culture. In ACM SIGCSE Bulletin (Vol. 29, No. 1, pp. 106-110). ACM.

Girl Scouts of America. (2014). Girl Scouts | For Girls. Retrieved from http://forgirls.girlscouts.org/home/badgeexplorer

Hazari, Z., Sadler, P. M., \& Sonnert, G. (2013). The science identity of college students: Exploring the intersection of gender, race, and ethnicity. Journal of College Science Teaching, 42(5), 82-91.

Hazari, Z., Sonnert, G., Sadler, P. M., \& Shanahan, M. C. (2010). Connecting high school physics experiences, outcome expectations, physics identity, and physics career choice: A gender study. Journal of Research in Science Teaching, 47(8), 978-1003.

Lagesen, V. A. (2007). The strength of numbers strategies to include women into computer science. Social Studies of Science, $37(1), 67-92$.

Lelliott, A., \& Rollnick, M. (2010). Big ideas: A review of astronomy education research 1974-2008. International Journal of Science Education, 32(13), 1771-1799.

Margolis, J., Fisher, A., \& Miller, F. (2000). The anatomy of interest: Women in undergraduate computer science. Women's Studies Quarterly, 28(1), 104-127.

Miller, S. T., \& James, C. R. (2011). The effect of animations within PowerPoint presentations on learning introductory astronomy. Astronomy Education Review, 10(1), 010202.

Potvin, G., Hazari, Z., Tai, R. H., \& Sadler, P. M. (2009). Unraveling bias from student evaluations of their high school science teachers. Science Education, 93(5), 827-845.

Riegle-Crumb, C., Moore, C., \& Ramos-Wada, A. (2011). Who wants to have a career in science or math? Exploring adolescents' future aspirations by gender and race/ethnicity. Science Education, 95(3), 458-476.

Rossiter, M. W. (1997). Which science? Which women? Osiris, 12(1), 169-185.

Sadler, P. M., Sonnert, G., Hazari, Z., \& Tai, R. (2012). Stability and volatility of STEM career interest in high school: A gender study. Science Education, 96(3), 411-427.

Shettle, C., Roey, S., Mordica, J., Perkins, R., Nord, C., Teodorovic, J., ... \& Brown, J. (2007). The nation's report card [TM]: America's high school graduates. National Center for Education Statistics.

Singh, K., Allen, K. R., Scheckler, R., \& Darlington, L. (2007). Women in computer-related majors: A critical synthesis of research and theory from 1994-2005. Review of Educational Research, 77(4), 500-533.

Slater, S. J. (2010). The educational function of an astronomy REU program as described by participating women. Ph.D. Dissertation, University of Arizona. Available online at: http://gradworks.umi.com/3412598.pdf

Tatge, C. B., Slater, S. J., Schleigh, S. P., Slater, T. F., Bretones, P. S., McKinnon, D., \& Heyer, I. (2016). iSTAR First light: Characterizing astronomy education research dissertations in the iSTAR database. Journal of Astronomy \& Earth Sciences Education, 3. 


\section{APPENDIX A - ADDITIONAL TABLES}

The following tables show raw data for the Sankey diagram displayed in Figure 2. These tables show the numbers of students who transitioned their interest between fields for the periods between middle school and the beginning of high school (Table A), the beginning of high school and the end of high school (Table B), and the end of high school and college (Table C). Note that student counts are not whole numbers because students were allowed to list as many fields as they wanted, and we have weighted the data accordingly.

Table A. The numbers of students who were interested in each field on the left during middle school, who subsequently were interested in each field listed along the top during the beginning of high school.

\begin{tabular}{l|c|c|c|c}
\hline & BHS Astronomy & BHS STEM & BHS STEM-Related & BHS Other \\
\hline MS Astronomy & 78.6 & 290.2 & 91.7 & 248.2 \\
\hline MS STEM & 110.4 & 2184.8 & 462.2 & 960.0 \\
\hline MS STEM-Related & 56.1 & 712.7 & 2517.4 & 1130.1 \\
\hline MS Other & 99.9 & 1165.6 & 1022.8 & 5064.1 \\
\hline
\end{tabular}

Table B. The numbers of students who were interested in each field on the left during the beginning of high school, who subsequently were interested in each field listed along the top at the end of high school.

\begin{tabular}{l|c|c|c|c}
\hline & EHS Astronomy & EHS STEM & EHS STEM-Related & EHS Other \\
\hline BHS Astronomy & 37.1 & 156.7 & 33.1 & 133.0 \\
\hline BHS STEM & 78.2 & 2400.9 & 528.5 & 1306.2 \\
\hline BHS STEM-Related & 20.1 & 615.7 & 2407.0 & 1146.6 \\
\hline BHS Other & 72.6 & 1158.0 & 994.3 & 4993.3 \\
\hline
\end{tabular}

Table C. The numbers of students who were interested in each field on the left at the end of high school, who subsequently were interested in each field listed along the top during college.

\begin{tabular}{l|c|c|c|c}
\hline & College Astronomy & College STEM & College STEM-Related & College Other \\
\hline EHS Astronomy & 27.8 & 94.0 & 20.6 & 72.6 \\
\hline EHS STEM & 61.5 & 2825.2 & 373.2 & 926.6 \\
\hline EHS STEM-Related & 10.3 & 360.4 & 2865.0 & 635.0 \\
\hline EHS Other & 35.4 & 689.2 & 581.0 & 5672.9 \\
\hline
\end{tabular}




\section{APPENDIX B - DATA COLLECTION INSTRUMENT}

In this study we used data from 3 questions of the OPSCI survey. One question (gender) is not shown, while the other two (career interests and OST activities) are displayed below.

Figure A. Question 1 from the OPSCI survey, which asked students to indicate their career interests during middle school, at the beginning of high school, the end of high school, and at the start of college.

1. Which of the following describes what you want(ed) to be in middle school, high school (beginning and end), and in college? Mark all that apply. Leave blank those that do not apply.

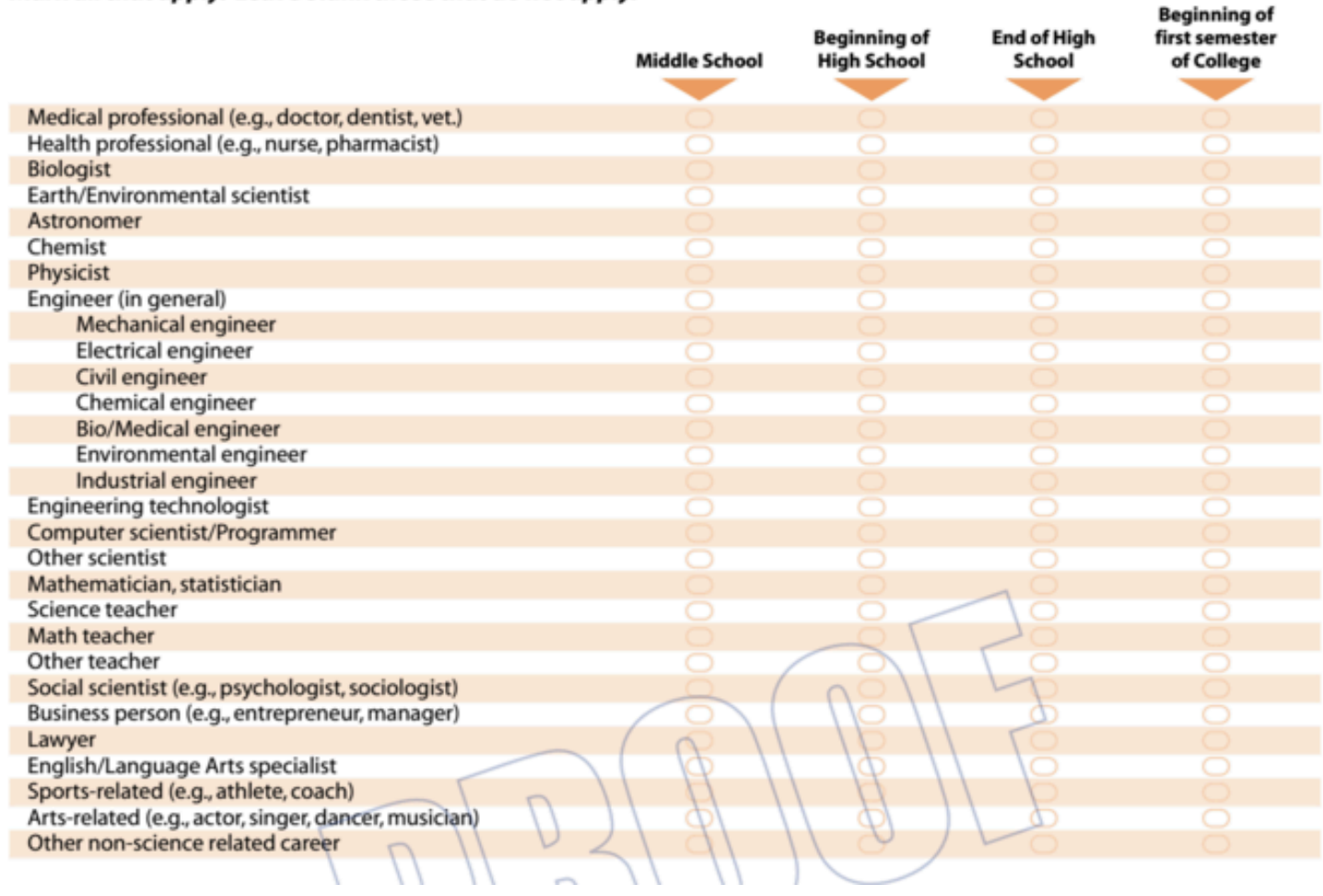

Figure B. Question 16 from the OPSCI survey, which asked students to indicate which outside-of-school time activities they participated in during Kindergarten-grade 4, grades 5-8, and grades 9, 10, 11, and 12.

16. Which of the following interests and experiences did you have while growing up?

If you had these interests or experiences,
Tinkered with mechanical devices (e.g., rifle, bow and arrow, car jack, pulleys,
wheelbarrow, sewing machine)
Tinkered with electrical devices (e.g., cars, batteries and bulbs, radio, TV)
Mixed chemical/materials. Engaged with chemistry sets, kitchen chemistry
Took care of or trained an animal
Planted seeds, watched plants grow, watched animal behavior, collected things
in nature (e.g., butterflies, rocks)
Observed or studied stars and other astronomical objects
Participated in science groups/clubs/camps
Participated in science/math competition(s)
Read/Watched non-fiction science
Read/Watched science fiction
Played computer/video games
Wrote computer programs or designed web pages
Talked with friends or family about science

